\title{
Effect of maternal body mass index on pregnancy outcomes
}

\author{
Sonal Bhuyar*, Neha Dharmale \\ Department of Obstetrics and Gynecology, Dr. Punjabrao Deshmukh Memorial Medical College, Amravati,
} Maharashtra, India

Received: 18 September 2018

Accepted: 22 October 2018

\section{*Correspondence:}

Dr. Sonal Bhuyar,

E-mail: drsonalbhuyar14@gmail.com

Copyright: (C) the author(s), publisher and licensee Medip Academy. This is an open-access article distributed under the terms of the Creative Commons Attribution Non-Commercial License, which permits unrestricted non-commercial use, distribution, and reproduction in any medium, provided the original work is properly cited.

\section{ABSTRACT}

Background: BMI is widely accepted as a better measure of underweight or overweight than weight alone. The developing countries including India are facing a dual burden of undernutrition and obesity. Extremes of BMI in pregnancy have been associated with multiple complications affecting maternal and perinatal outcome. The objectives of the present study was to observe distribution of antenatal patients in underweight, normal, overweight and obese categories according to booking BMI and to examine the association of BMI with obstetric and perinatal outcomes in singleton pregnancies.

Methods: This was an observational prospective study with a sample size of 610 patients carried out during the period Dec 2016 to Nov 2017 in Dr PDMMC, Amravati. The antenatal patients were categorized into four categories of BMI according to WHO classification and pregnancy outcomes were compared.

Results: Depending on booking BMI, $73.8 \%$ patients enrolled in the study had normal booking BMI and $16.7 \%$, $8.5 \%$ and $1 \%$ were underweight, overweight and obese respectively. Postdatism, preterm births, induction of labour, LSCS and prolonged hospital stay were commoner in overweight patients while IUGR, oligohydramnios and $\mathrm{BOH}$ were seen more in underweight group. Neonatal resuscitation and neonatal complications were common in both underweight and overweight patients as compared to normal BMI patients.

Conclusions: Based on this study, we conclude that majority of antenatal patients being catered in our hospital have normal BMI. Adverse maternal and perinatal outcomes are seen more commonly with the extremes of BMI.

Keywords: Booking BMI, Maternal and perinatal outcome

\section{INTRODUCTION}

The developing countries like India are facing a dual burden of nutritional problems, with undernourished and underweight women on one side and overweight and obese women on the other side. We were yet struggling to eradicate undernutrition and anaemia from our country and we are already facing an epidemic of obesity in the 21 st century probably due to the transition from traditional diets and lifestyles to western diets. According to National Family Health Survey (NFHS-3) in 2005-06 in India, only $52 \%$ of women had a normal Body Mass
Index (BMI). Thirteen percent of women were overweight or obese while $36 \%$ were undernourished. ${ }^{1}$ NFHS-4 in 2015-16 states that number of obese people has doubled in the last 10 years. $^{2}$

BMI is widely accepted as a better measure of under or overweight than weight alone. It is an index of weightfor- height and is calculated by dividing a person's weight in kilograms by square of height in meters $\left(\mathrm{kg} / \mathrm{m}^{2}\right)$. Increased BMI in pregnancy is related to increasing incidence of preeclampsia, gestational diabetes, postdatism, macrosomia, induction of labour 
and increased operative interferences; while low BMI is associated with preterm delivery, low birth weight babies, anemia etc. $^{3}$

The need for present study was to assess the distribution of antenatal women being catered in our hospital in four categories of BMI and to evaluate whether BMI significantly affects pregnancy outcome. The objectives of the present study were to study distribution of antenatal patients in underweight, normal, overweight and obese categories according to booking BMI, to find out average weight gain in each of the four categories of $\mathrm{BMI}$, to examine the association of BMI with obstetric and perinatal outcomes in singleton pregnancies.

\section{METHODS}

This prospective observational study was conducted in the dept. of Obstetrics and Gynecology, Dr PDMMC, Amravati for a period of one year from December 2016 to November 2017 after obtaining clearance from the Hospital Ethical Committee.

Table 1: WHO classification of nutritional status based on BMI.

\begin{tabular}{ll} 
Classification & BMI $\left(\mathrm{kg} / \mathrm{m}^{2}\right)$ \\
\hline Underweight & $<18.5$ \\
\hline Normal & $18.5-24.9$ \\
\hline Overweight & $25-29.9$ \\
\hline Obese & $\geq 30$ \\
\hline
\end{tabular}

Women with singleton pregnancies who registered in first trimester, came for regular antenatal visits and delivered at PDMMC with cephalic presentation were included in the study. Women with multiple pregnancies, abnormal presentation, previous LSCS and preexisting medical disorders were excluded from the study.

Out of total 1782 antenatal registrations from Dec 2016 to May 2017, 648 patients fulfilling the inclusion criteria were enrolled in the study.

Detailed history, general and abdominal exam findings were noted in a predefined proforma. Maternal height was measured by stadiometer and weight was recorded on digital weighing scale and Booking BMI was calculated. Pre- pregnancy BMI is not reliably obtained in our population due to lack of preconceptionally checkups, poor recall of weight by patients and unplanned pregnancies.

Besides, first trimester weight usually correlates with prepregnancy weight. Enrolled patients were followed regularly in antenatal OPD and complications were noted if any. When admitted for delivery, weight was recorded, and second BMI was calculated. Intra partum and post- partum events and neonatal details were also recorded in detail. Out of 648 patients, 610 delivered at our hospital and constituted our sample population and rest 38 (5.9\%) patients were considered drop- outs. The booking BMI was used to divide the patients into underweight, normal, overweight and obese categories according to the WHO classification. ${ }^{4}$ The effect of booking BMI on pregnancy outcomes in each group was studied with respect to the following variables:

- Pre- pregnancy variables: Age, parity.

- Antenatal variables: Preeclampsia, PIH, gestational diabetes, preterm delivery, postdatism, IUGR, macrosomia, prolonged antenatal stay etc.

- Intrapartum variables: Induction of labour, mode of delivery, failed induction, intra-op complications, need for BT etc.

- Postpartum variables: PPH, prolonged hospital stay, impaired wound healing, any infections.

- Neonatal variables: Low birth weight $(<2.5 \mathrm{~kg})$, big baby $(>3.5 \mathrm{~kg})$, preterm, need for resuscitation, admission to NICU, neonatal complications, intrauterine death/ stillbirth/ neonatal death.

After studying the occurrence of above variables in different groups of BMI, the information gathered was converted into tabulations and graphical forms.

The sample size was calculated using Open Epi software, version 3. Considering the prevalence of PIH from the reference article of $38.75 \%$, sample size was calculated at $95 \%$ C.I. and 5\% error and it came out to be 365 5. Data was entered in MS- Excel and was analyzed in SPSS software version- 16 .

After performing the statistical analysis, mean and percentages were calculated and chi- square test of significance was applied. $\mathrm{p}<0.05$ was considered as statistically significant.

\section{RESULTS}

A total of 610 patients were included in the study. Depending on booking BMI, 450 (73.8\%) patients enrolled in the study had normal booking BMI, 102 $(16.7 \%)$ were underweight, $52(8.5 \%)$ were overweight and $6(1 \%)$ were obese.

The mean age of the study group was 25.3 years. $51 \%$ pts were in age group 25-34 years, $47 \%$ in 15-24 age group and only $2 \%$ in elderly age group. $344(56.4 \%)$ patients registered in this study were primigravida and 266 $(43.6 \%)$ were multigravida.

In all categories of BMI, primi were more common except in obese group with 3 primi and multigravida each (Table 2). 
Table 2: Pre-pregnancy variables.

\begin{tabular}{|llllll|}
\hline Age (years) & Underweight (102) & Normal (450) & Overweight (52) & Obese (6) & Total (610) \\
\hline $15-24$ & 53 & 208 & 24 & 2 & $287(47 \%)$ \\
$25-34$ & 47 & 233 & 27 & 4 & $311(51 \%)$ \\
\hline $35-44$ & 2 & 9 & 1 & 0 & $12(2 \%)$ \\
\hline Gravidity & & 258 & 28 & 3 & $344(56.4 \%)$ \\
\hline Primigravida & 55 & 192 & 24 & 3 & $266(43.6 \%)$ \\
\hline Multigravida & 47 & & & & \\
\hline
\end{tabular}

Table 3: Weight gain during pregnancy.

\begin{tabular}{|c|c|c|c|c|c|}
\hline & Underweight (102) & Normal (450) & Overweight (52) & Obese (6) & Total (610) \\
\hline \multicolumn{6}{|c|}{ Weight gain (kg) } \\
\hline $0-5$ & 8 & 28 & 1 & 1 & 38 \\
\hline $6-10$ & 46 & 295 & 38 & 3 & 382 \\
\hline $11-15$ & 45 & 119 & 8 & 0 & 172 \\
\hline $16-20$ & 3 & 8 & 5 & 2 & 18 \\
\hline
\end{tabular}

In all categories of BMI, weight gain between $6-15 \mathrm{~kg}$ was most common. $8(21 \%)$ patients gaining weight less than $5 \mathrm{~kg}$ were from underweight group as compared to 2
(5.2\%) from overweight and obese group. Among 18 patients gaining weight between 16- $20 \mathrm{~kg}, 7$ (38.9\%) were from overweight and obese group while $3(16.7 \%)$ were from underweight group (Table 3).

Table 4: Antenatal variables.

\begin{tabular}{|c|c|c|c|c|c|}
\hline & Underweight (102) & Normal (450) & Overweight (52) & Obese (6) & Total $(610)$ \\
\hline \multicolumn{6}{|c|}{ Antenatal complications } \\
\hline Postdatism & 16 & 91 & 7 & 2 & 116 \\
\hline Preterm & 13 & 55 & 4 & 2 & 74 \\
\hline PIH/eclampsia & 3 & 20 & 2 & 0 & 25 \\
\hline PROM/PPROM & 5 & 15 & 2 & 0 & 22 \\
\hline IUGR & 3 & 12 & 1 & 0 & 16 \\
\hline Oligohydramnios & 6 & 7 & 2 & 0 & 15 \\
\hline $\mathrm{BOH}$ & 4 & 10 & 0 & 0 & 14 \\
\hline Anaemia & 2 & 3 & 0 & 0 & 5 \\
\hline Polyhydramnios & 0 & 5 & 0 & 0 & 5 \\
\hline Multiple & 12 & 52 & 10 & 2 & 76 \\
\hline $\begin{array}{l}\text { Total (\% within BMI } \\
\text { category) }\end{array}$ & $64(62.7 \%)$ & $270(60.0 \%)$ & $28(53.8 \%)$ & $6(100.0 \%)$ & $368(60.3 \%)$ \\
\hline
\end{tabular}

Table 5 Intrapartum variables.

\begin{tabular}{|llllll|}
\hline \multicolumn{2}{l}{ Onderweight (102) } & Normal (450) & Overweight (52) & Obese (6) & Total (610) \\
\hline Spontaneous & 87 & 349 & 35 & 3 & 474 \\
\hline Induced & 11 & 61 & 11 & 2 & 85 \\
\hline Total & 98 & 410 & 46 & 5 & 559 \\
\hline Mode of delivery & & & & 3 & 326 \\
\hline Normal & 56 & 236 & 31 & 0 & 47 \\
\hline Instrumental & 6 & 37 & 4 & 3 & 237 \\
\hline LSCS & 40 & 177 & 17 & & \\
\hline
\end{tabular}


Average weight gain in each category was also calculated and was found to be $9.7 \mathrm{~kg}$ in underweight, $8.9 \mathrm{~kg}$ in normal, $9.4 \mathrm{~kg}$ in overweight and $10.7 \mathrm{~kg}$ in obese groups.

$368(60.3 \%)$ patients had one or more antenatal complications, amongst which $31.5 \%$ had postdatism, $20.1 \%$ preterm, $6.8 \% \mathrm{PIH}, 6.0 \%$ PROM, approx $4 \%$ each had IUGR, oligohydramnios and $\mathrm{BOH}$ as single complication. $76(20.6 \%)$ patients had more than one complication. Rare complications observed in the study were ARDS, fibroid with pregnancy, viral hepatitis, DIC and grade I retinopathy. Comparing percentages within BMI category, antenatal complications were observed in $50-60 \%$ of patients in all categories of BMI except in obese category where all patients developed either single or multiple complications. Postdatism was found in $33.3 \%$ in obese group, while $15.7 \%$ and $20.2 \%$ in UW and normal groups respectively. Preterm births were also found in $33.3 \%$ in obese patients, which was higher than all other categories of BMI. Multiple complications were observed more in higher BMI patients. $19.2 \%$ and $33.3 \%$ pts in OW and obese groups had multiple complications as compared to $11.8 \%$ in UW and $11.6 \%$ in normal groups. IUGR $(2.9 \%)$, oligohydramnios $(5.9 \%)$, PROM $(4.9 \%)$ and $\mathrm{BOH}(3.9 \%)$ were found to be more common in UW groups (Table 4).

$559(91.6 \%)$ patients out of 610 were given trial of labour, of which 85 (15.2\%) were induced. Comparing labour onset in patients given trial of labour, $25.5 \%$ of $\mathrm{OW}$ and obese patients required induction as compared to $11.2 \%$ patients in UW category and $14.9 \%$ in normal BMI category. $61.2 \%$ pts delivered vaginally amongst which $7.7 \%$ were instrumental deliveries, while $38.8 \%$ delivered by LSCS. Vaginal deliveries constituted approx $60-70 \%$ of total deliveries in all categories of BMI except in obese group where $50 \%$ patients underwent LSCS (Table 5).

30 (4.9\%) patients had PPH in this study. PPH was observed in $7-8 \%$ patients in underweight and overweight categories while $4 \%$ in normal BMI patients. Among patients with PPH, 22 had atonic, 4 had traumatic and 4 had atonic and traumatic PPH both. 3 patients required uterine artery ligation, one required internal iliac artery ligation and obstetric hysterectomy was done in one patient. $40(6.6 \%)$ patients required blood transfusion. $9.8 \%$ pts in underweight category required blood and $6 \%$ each in normal and overweight category. Prolonged postnatal stay was considered as more than 4 days in normal and instrumental deliveries and more than 10 days for LSCS patients. $7.9 \%$ patients stayed longer than expected due to postnatal or neonatal complications. Prolonged postnatal stay was observed in $33.3 \%$ in obese category as compared to $7-10 \%$ in other categories. Postnatal complication rate in UW and Normal BMI category was $9.8 \%$ and $9.3 \%$ respectively while $13.5 \%$ in OW and $50 \%$ in obese category (Table 6). Among 14 patients with impaired wound healing, 4 had wound discharge and required only dressing, while 10 patients had wound gape of which 8 patients had LSCS wound gape, 1 had episiotomy gape and 1 had puerperal tubectomy gape. In miscellaneous category, 3 patients had Urinary tract infection, 3 had anaemia, 2 had PIH with Diabetes, 1 each urinary retention and chest pain, 1 had undergone Obstetric hysterectomy and 2 patients required ICU admission of which 1 required ventilator support.

Table 6: Postpartum variables.

\begin{tabular}{|llllll|}
\hline & Underweight (102) & Normal (450) & Overweight (52) & Obese (6) & Total (610) \\
\hline PPH (\% within BMI category) & $8(7.8 \%)$ & $18(4 \%)$ & $4(7.7 \%)$ & $0(0 \%)$ & $30(4.9 \%)$ \\
\hline Need for blood transfusion & $10(9.8 \%)$ & $27(6 \%)$ & $3(5.8 \%)$ & $0(0 \%)$ & $40(6.6 \%)$ \\
\hline Prolonged hospital stay & $9(8.8 \%)$ & $32(7.1 \%)$ & $5(9.6 \%)$ & $2(33.3 \%)$ & $48(7.9 \%)$ \\
\hline PNC complications & & & & & \\
\hline Impaired wound healing & 2 & 11 & 1 & 0 & 14 \\
\hline Anaemia & 2 & 6 & 2 & 0 & 11 \\
\hline Fever & 1 & 7 & 1 & 0 & 9 \\
\hline Baby in NICU & 2 & 6 & 1 & 2 & 9 \\
\hline PIH & 3 & 3 & 1 & 0 & 9 \\
\hline Miscellaneous & 0 & 9 & 1 & $3(50 \%)$ & $62(10.2 \%)$ \\
\hline Total & $10(9.8 \%)$ & $42(9.3 \%)$ & $7(13.5 \%)$ & & 1 \\
\hline
\end{tabular}

Various neonatal variables were also compared in different categories of BMI. $68.9 \%$ patients delivered between 37-40 weeks of gestation, $19 \%$ were postdated and $12.1 \%$ delivered preterm. Mean gestational age at delivery in the study was 38.4 wks. Majority $(75.1 \%)$ of patients delivered babies with a birth weight between 2.5 -
$3.5 \mathrm{~kg} .21 .8 \%$ babies were LBW and $3.1 \%$ weighed $>3.5$ $\mathrm{kg}$.

Percentage of LBW babies was slightly less $(15.5 \%)$ in OW and obese groups as compared to UW (20.6\%) and Normal BMI (22.9\%) groups. Mean birth weight in the 
study was found to be $2.71 \mathrm{~kg}$. Unfavourable neonatal outcome was seen in only $3 \%$ of patients in the form of 12 stillbirths and 6 early neonatal deaths.

Among 12 stillbirths, 7 patients were admitted with intrauterine death and 5 were intra partum deaths. Total
$63(10.3 \%)$ neonates required resuscitation. $15.7 \%$ and $16.7 \%$ babies born to women in UW and obese categories respectively needed resuscitation, while $10 \%$ in normal category. $96(15.7 \%)$ babies required NICU admission and percentages within all BMI categories were found to be comparable (Table 7).

Table 7: Neonatal variables.

\begin{tabular}{|c|c|c|c|c|c|}
\hline & Underweight (102) & Normal (450) & Overweight (52) & Obese (6) & Total $(610)$ \\
\hline \multicolumn{6}{|l|}{ GA at delivery (weeks) } \\
\hline$<37$ & 13 & 55 & 4 & 2 & $74(12.1 \%)$ \\
\hline $37-40$ & 73 & 304 & 41 & 2 & $420(68.9 \%)$ \\
\hline$>40$ & 16 & 91 & 7 & 2 & $116(19 \%)$ \\
\hline \multicolumn{6}{|l|}{ Birth weight (kg) } \\
\hline$<2.5$ & 21 & 103 & 7 & 2 & $133(21.8 \%)$ \\
\hline $2.5-3.0$ & 67 & 250 & 32 & 3 & $352(57.7 \%)$ \\
\hline $3.1-3.5$ & 12 & 82 & 11 & 1 & $106(17.4 \%)$ \\
\hline$>3.5$ & 2 & 15 & 2 & 0 & $19(3.1 \%)$ \\
\hline \multicolumn{6}{|l|}{ Neonatal outcome } \\
\hline Alive & 100 & 435 & 51 & 6 & $592(97 \%)$ \\
\hline Stillbirth & 2 & 9 & 1 & 0 & $12(2 \%)$ \\
\hline Early NND & 0 & 6 & 0 & 0 & $6(1 \%)$ \\
\hline Need for resuscitation & 16 & 45 & 1 & 1 & $63(10.3 \%)$ \\
\hline NICU admission & 18 & 71 & 6 & 1 & $96(15.7 \%)$ \\
\hline
\end{tabular}

$102(16.7 \%)$ babies had neonatal complications, common amongst which were preterm LBW, IUGR LBW, meconium stained liquor and requirement of resuscitation. Miscellaneous category included septicemia, cephalhaematoma, congenital heart disease, inborn errors of metabolism and absent radius. Though rate of neonatal complications observed in all categories of BMI was comparable, differences were noted in few complications; such as meconium stained liquor was found in $4.9 \%$ and $3.8 \%$ in UW and OW categories respectively as compared to $1.8 \%$ in normal BMI group. Neonatal jaundice was observed in $0.7 \%$ patients with normal BMI, while $1.0 \%$ and $1.9 \%$ in UW and OW groups. Neonates born with birth weight more than $3.5 \mathrm{~kg}$ were found in $3.8 \%$ in OW group as compared to $0.7 \%$ in normal BMI group (Table 8).

Table 8: Neonatal complications.

\begin{tabular}{|llllll|}
\hline NN complications & Underweight (102) & Normal (450) & Overweight (52) & Obese (6) & Total (610) \\
\hline Preterm LBW & 2 & 16 & 0 & 1 & $19(3.1 \%)$ \\
\hline IUGR LBW & 2 & 11 & 1 & 0 & $14(2.3 \%)$ \\
\hline Meconium liquor & 5 & 8 & 2 & 0 & $15(2.5 \%)$ \\
\hline Resuscitation & 8 & 26 & 0 & 0 & $34(5.6 \%)$ \\
\hline Jaundice & 1 & 3 & 1 & 0 & $5(0.8 \%)$ \\
\hline Big baby & 0 & 3 & 2 & 0 & $5(0.8 \%)$ \\
\hline Fever & 0 & 4 & 0 & 0 & $4(0.7 \%)$ \\
\hline Miscellaneous & 0 & 5 & 1 & 0 & $6(1 \%)$ \\
\hline Total (\% within BMI category) & $18(17.6 \%)$ & $76(16.9 \%)$ & $7(13.5 \%)$ & $1(16.7 \%)$ & $102(16.7 \%)$ \\
\hline
\end{tabular}

\section{DISCUSSION}

The Quetelet index or BMI was devised between 18301850. Because BMI is derived from simple measurements like height and weight, it is clearly inexpensive but effective measure to compare pregnancy outcomes with relation to weight gain during pregnancy. This study adds to the increasing body of evidence that suggests that 
women with low and high BMI are both predisposed to complications in pregnancy.

In present study, $21 \%$ of patients with weight gain less than $5 \mathrm{~kg}$ were from UW group while $39 \%$ of patients gaining weight between $16-20 \mathrm{~kg}$ were from OW group, highlighting the importance of dietary advice according to the booking BMI right from the first trimester itself. Ideally UW women should gain weight between 12.7- 18 $\mathrm{kg}$ and $\mathrm{OW}$ women only $7-11 \mathrm{~kg} 6$. Addo $\mathrm{V} \mathrm{N}$ also found a statistically significant high total weight gain $(>16 \mathrm{~kg})$ in overweight and obese patients as compared to normal BMI patients. ${ }^{7}$

All patients in obese category and $62.7 \%$ in UW group in the present study developed antenatal complications. Among the obese patients, 33.3\% patients each had postdatism, preterm labour and multiple complications (mainly combination of PIH, IUGR, anaemia, oligohydramnios etc), higher than all other categories. This was in accordance with a study by Donna $\mathrm{R} \mathrm{H}$ et al which showed that prolonged or postterm pregnancy was common with increasing prepregnancy weight and increasing maternal weight gain. ${ }^{8}$ Also, in a study by Deepika Jain et al, risk of PIH was found to be eight times higher in obese patients than those with normal BMI. ${ }^{9}$ The study by Baeten et al quotes increased risk of preterm births in obese patients..$^{10}$ Bianco et al also found no association between BMI and preterm labour, while in a systematic review and meta-analysis by Han $\mathrm{Z}$ et al, it was determined that singletons born to UW women have higher risks of overall spontaneous and induced preterm birth and LBW $<2.5 \mathrm{~kg}$. ${ }^{11,12}$ The present study observed that low birth weight babies were found to be more in UW group though the difference was not statistically significant.

In the present study, induction of labour was required in $25 \%$ of obese and OW patients as compared to $11.2 \%$ of UW and $14.9 \%$ of normal BMI patients. These results corroborated with the findings of a study by Meenakshi et al where a significantly higher rate of induction of labour was found in OW (26.9\%) and obese $(30.9 \%)$ patients than normal BMI patients $(6.8 \%){ }^{5}$ This study also showed a higher LSCS rate in OW (45.1\%) and obese (52.5\%) patients as compared to normal BMI patients which supported findings of present study showing that $50 \%$ of obese patients underwent LSCS. ${ }^{5}$

The rate of PPH in present study was found to be higher in UW as well as OW patients (7-8\%) as compared to normal BMI patients though the difference was not statistically significant. In a study by Deepika Jain et al, the maximum occurrence of PPH (14.29\%) was in obese group. ${ }^{9}$ Also Sebire et al observed an increase in PPH with an increase in BMI. ${ }^{13}$ In contrast to these studies, Paglia $\mathrm{M} \mathrm{J}$ et al found that women with $\mathrm{BMI}<30$ and Hispanic women are more likely to have severe PPH. ${ }^{14}$ Bianco et al observed no such relation of BMI and PPH. ${ }^{11}$ In addition, in present study, blood transfusions were required more in UW $(9.8 \%)$ as compared to $6 \%$ in normal and $\mathrm{OW}$ patients reflecting the undernourished state of UW group.

In the present study, prolonged postnatal stay was observed in $33.3 \%$ in obese category as compared to 7 $10 \%$ in other categories. Postnatal complication rate in UW and normal BMI category was $9.8 \%$ and $9.3 \%$ respectively while $13.5 \%$ in $\mathrm{OW}$ and $50 \%$ in obese category. Meenakshi et al in their study observed that prolonged hospital stay $(33.8 \%)$, impaired wound healing $(38.1 \%)$, urinary tract infection $(12.5 \%)$ and pyrexia $(18.8 \%)$ had a higher incidence in obese group. ${ }^{5}$

$15.7 \%$ and $16.7 \%$ babies born to women in present study UW and obese categories respectively needed resuscitation, while $10 \%$ in normal category. Unfavourable neonatal outcome and NICU admission were comparable in all categories of BMI. In a study by Tharihalli C, low APGAR score at birth was seen more in obese $(24 \%)$ and in UW (17.3\%) groups. ${ }^{15}$

Neonates born with birth weight more than $3.5 \mathrm{~kg}$ were found in $3.8 \%$ in OW group as compared to $0.7 \%$ in normal BMI group. This result is in accordance with the study by Weiss JL which showed that obese women have an $18-26 \%$ increased chance of delivering large for date infants. ${ }^{16}$ In present study, few neonatal complications like jaundice and meconium stained liquor also were found to be more in UW and OW categories as compared to normal BMI patients.

\section{CONCLUSION}

Based on this study, we conclude that majority of antenatal patients being catered in our hospital have normal BMI. Adverse maternal and perinatal outcomes are associated with extremes of BMI. A prepregnancy counseling and general awareness regarding diet and desired weight gain according to booking BMI is essentially required for better pregnancy outcomes.

\section{ACKNOWLEDGMENTS}

Authors would like to thank Dr. Manjusha Deotale, Assistant Professor, PSM department, Dr. PDMMC Amravati for her contribution in statistical analysis of data in SPSS software.

Funding: No funding sources

Conflict of interest: None declared

Ethical approval: The study was approved by the Institutional Ethics Committee

\section{REFERENCES}

1. International Institute for population sciences. Key Indicators for India from NFHS-3. 2006. Available at: www.nfhsindia.org/pdf/India. 
2. India's obesity doubled in 10 years: NFHS-4- Down To Earth. Available at www.downtoearth.org.in

3. Bhattacharya S, Campbell DM, Liston WA, Bhattacharya S. Effect of body mass index on pregnancy outcomes in nulliparous women delivering singleton babies. BMC Public Health. 2007;7(1):168.

4. World Health Organization. Global strategy on diet, Physical activity and Health. WHO publication, 2004.

5. Meenakshi RS, Sharma NR, Kushwaha KP, Aditya $\mathrm{V}$. Obstetric behaviour and pregnancy outcome in overweight and obese women. J Obstet Gynecol India. 2012;62(3):276-80.

6. Healthy range of weight gain for Indian women during pregnancy. Available at www.healthwiseindian.com

7. Addo VN. Body mass index, weight gain during pregnancy and obstetric outcome. Ghana Med J. 2010;44(2):64-9.

8. Donna RH, Cheng YW, Caughey AB. Effect of maternal weight on postterm delivery. Journal of Perinatology, California. 2012;32(2):85-90.

9. Deepika J, Rakesh K, Veena C, Sushila K. Effect of body mass index on pregnancy outcomes in nulliparous women delivering singleton babies: Observational study. J Obstet Gynecol India. 2012,62(4):429-31.

10. Baeten JM, Bukusi EA, Lambe M. Pregnancy complications and outcomes among overweight and obese nulliparous women. Am J Public Health 2001; 91(3):436-40.
11. Baeten JM, Bukusi EA, Lambe M. Pregnancy outcome and weight gain recommendations for the morbidly obese woman. Obstet Gynecol. 1998;91(3): 97-102.

12. Han Z, Mulla S, Beyene J, Liao G, McDonald SD. Maternal underweight and the risk of preterm birth and low birth weight: a systematic review and metaanalysis. Indian J Epidemiol. 2011;40(1):65-101.

13. Sebire NJ, Jolly M, Harris JP et al. Maternal obesity and pregnancy outcome. A study of 287,213 pregnancies in London. Int J Obes. 2001;25(8):117582.

14. Paglia MJ, Grotegut CA, Johnson LNC Thames B, James AH. Body mass index and severe Pregnancy induced hypertension. Gynecol Obstet Invest. 2012; 73(1):70-4.

15. Tharihalli C, Thathagari V. Study of correlation between maternal body mass index with maternal and perinatal outcome. Int J Reprod Contracept Obst Gynecol. 2017;6(1):164-7.

16. Weiss JL, Malone FD, Emig D, Ball RH, Nyberg DA, Comstock CH. Obesity, obstetric complications and caesarean delivery rate- a population based screening study. Am J Obstet Gynecol. 2004;190(4):1091-7.

Cite this article as: Bhuyar S, Dharmale N. Effect of maternal body mass index on pregnancy outcomes. Int J Reprod Contracept Obstet Gynecol 2018;7:4949-55. 